\title{
Heart Disease is the Leading Cause of Death for Women - We must Change the Status Quo
} Gláucia Maria Moraes de Oliveira1 ${ }^{\text {(i) }}$ and Claudio Tinoco Mesquita 2,3,4 (1)

Pós-graduação em Cardiologia da UFRJ, Universidade Federal do Rio de Janeiro (UFRJ), 1 Rio de Janeiro, RJ - Brazil Pós-Graduação em Ciências Cardiovasculares, Ebserh/HUAP, Universidade Federal Fluminense, ${ }^{2}$ Niterói, RJ - Brazil Hospital Pró-Cardíaco, ${ }^{3}$ Rio de janeiro, RJ - Brazil

Editor-in-Chief International Journal of Cardiovascular Sciences, Sociedade Brasileira de Cardiologia, ${ }^{4}$ Rio de Janeiro, RJ - Brazil
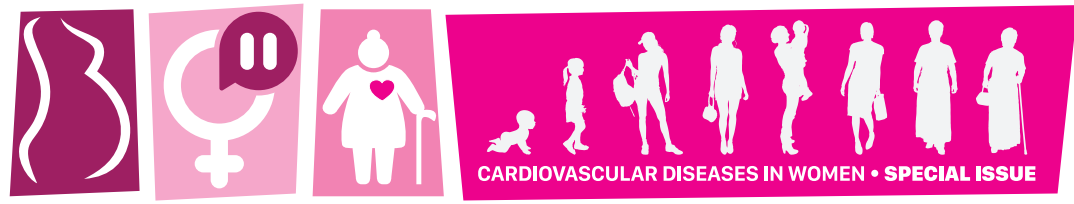

MEET WOMEN WHERE THEY ARE TO PROVIDE BETTER CARDIOVASCULAR CARE

According to the Continuous National Household Sample Survey, in 2019, the Brazilian population was composed of $48.2 \%$ men and $51.8 \%$ women. In the age group up to 24 years old, men and women accounted for $17.8 \%$ and $17.2 \%$ of the population, respectively, in 2019. From 25 years of age onwards, the proportion of women was higher than that of men in all age groups, $30.4 \%$ and $34.6 \%$, respectively, for men and women. On the other hand, life expectancy for men in that same year was 73.1 years, and, for women, it was 80.1 years. Therefore, it is important to build data about Brazilian women in all stages of their course of life. ${ }^{1}$

The greatest burden of death and disability among women worldwide is attributable to non-communicable diseases, especially cardiovascular diseases (CVD). Moreover, nearly $80 \%$ of non-communicable diseases occur in low-income and middle-income countries, such as Brazil. ${ }^{2}$ Marques-Santos and Oliveira highlighted the differences in CVD between female and male sex and emphasized the higher proportional mortality in Brazilian women. ${ }^{3}$ According to Global Burden of Disease 2019, in Brazil, CVD accounted for $22.42 \%$ of deaths in women, compared to $20.83 \%$ in men, considering all ages. ${ }^{4}$

In the same line, Parapid \& Bond highlight several aspects of the inequity unveiled by COVID-19 in women's lives, and they proposed actions to improve the careers of women in the frontline of the health-care sector. Finally, they conclude that "most importantly, as doctors, we know that, as long as there is a will, we tend to find a way, and, finally, if not us, then who?" That is our mission, to meet women where they are to provide better cardiovascular care. ${ }^{5}$

Several aspects of risk stratification in women have been shown in the original articles, especially those specific to the female sex, in a country like Brazil with different socioeconomic determinants. It is worth noting that cardiovascular risk in Brazilian women, mostly at young ages, has been changing in recent years, with increased obesity, diabetes, and arterial hypertension, in accordance with data from Global Burden of Disease 2019. ${ }^{4}$ However, most of them are preventable by means of healthy lifestyles at the population and individual levels.

Women are underdiagnosed and undertreated compared to men with the worst prognosis in various diseases, such as ischemic heart disease, myocardial infarction, mitral valve diseases, and infective endocarditis, as we can see in the articles in this issue. ${ }^{6-10}$

Dr. Fausto Pinto, President of the World Heart Federation, highlighted the necessity of getting gender equity and listed several suggestions proposed by the ACC's Cardiovascular Disease in Women Committee to reduce existing gaps. And he emphasizes that "a lot has been done, but a lot more still needs to be done. It is up to all of us to ensure that will happen". ${ }^{11}$ 
Brazil is a continent-sized country with great heterogeneity and local diversity due to socioeconomic and cultural aspects of women's lives. Therefore, it is fundamental to promote initiatives to increase knowledge about the importance of cardiovascular health in all women's life courses. Furthermore, it is crucial to better understand local disparities in women's cardiovascular health in order to define public policy and health care, reduce gaps, and promote gender equity in Brazilian health care. ${ }^{3}$

We would like to thank Dr. Roxana Mehran, Professor of Medicine and Director of Interventional Cardiovascular Research and Clinical Trials at the Zena and Michael A. Wiener Cardiovascular Institute at Mount Sinai, for accepting the invitation to co-edit this issue. Dr. Mehran is an international leader in cardiology, and she is involved in multiple activities that contribute to the empowerment of women in cardiology and to coping with cardiovascular disease in women. In addition to our special thanks to Dr. Mehran, we extend our thanks to all editors, authors, reviewers, contributors, translators,

\section{References}

1. Instituto Brasileiro de Geografia e Estatística. Pesquisa Nacional por Amostra de Domicílios Contínua - PNAD. Brasília: IBGE; 2019.

2. Oliveira GMM, Brant LCC, Polanczyk CA, Biolo A, Nascimento BR, Malta DC, et al. Cardiovascular Statistics - Brazil 2020. Arq Bras Cardiol. 2020;115(3):308439. doi: 10.36660/abc.20200812.

3. Marques-Santos C, Oliveira GMM. Are Women the Fragile Sex? Or are They the Singular Sex? Int J Cardiovasc Sci. 2021; 34(4):344-346. doi: https://doi. org/10.36660/ijcs.20210171.

4. Global Burden of Disease Study 2019 (GBD 2019) Results. Global Health Data Exchange Website. Seattle, WA: Institute for Health Metrics and Evaluation (IHME), University of Washington; 2019.

5. Parapid B, Bond RM. COVID-19: An Insult to Injury on Equity. Int J Cardiovasc Sci. 2021; 34(4):342-343. doi: https://doi.org/10.36660/ijcs.20210165.

6. Vogel B, Acevedo M, Appelman Y, Merz CNB, Chieffo A, Figtree GA, et al. The Lancet Women and Cardiovascular Disease Commission: Reducing the Global Burden by 2030. Lancet. 2021;397(10292):2385-438. doi: 10.1016/S01406736(21)00684-X. statisticians, and members of the editorial board of the International Journal of Cardiovascular Sciences who have undertaken the enormous effort to bring us this special issue.

We invite you to read this special issue that intends to understand better all aspects of cardiovascular health care in women in order to give them healthy lives wherever they are. We greatly appreciate all the women who helped us build this special edition, especially Ms. Tailane Rodrigues, who put forth all her best efforts to bring us this outstanding issue of the International Journal of Cardiovascular Sciences completely devoted to Brazilian women.

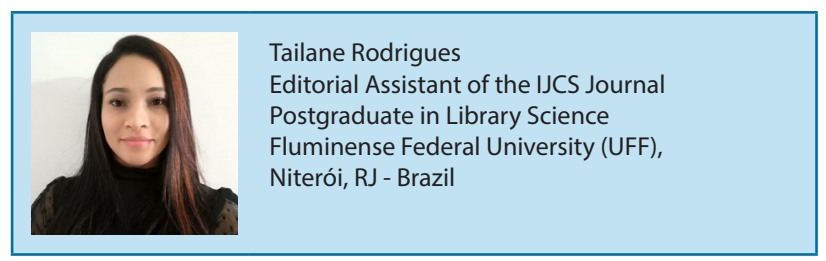

7. Ferreira MCM, Oliveira MV, Paiva MSM, Lemke V, Mangione F, Oliveira GMM. Closing the Gender Gap in Ischemic Heart Diseases and Myocardial Infarction. Int JCardiovasc Sci. 2021;34(4):471-483 doi: https://doi.org/10.36660/ ijcs.20210001.

8. Moreira JL, Barletta PHAAS, Baucia JA. Women Undergoing Mitral Valve Replacement: A Retrospective Analysis. Int J Cardiovasc Sci. 2021; 34(4):431-442. doi: https://doi.org/10.36660/ijcs.20200412.

9. Sousa C, Nogueira PJ, Pinto FJ. Gender Based Analysis of a Population Series of Patients Hospitalized with Infective Endocarditis in Portugal - How do Women and Men Compare? Int J Cardiovasc Sci. 2021; 34(4):347-355. doi: https://doi.org/10.36660/ijcs.20210032

10. Mehran R, Vogel B. Women and Cardiac Disease: A Special Issue. Int J Cardiovasc Sci. 2021; 34(4):338-339. doi: https://doi.org/10.36660/ ijcs.20210173.

11. Pinto FJ. Gender Equity: Time to Act. Int J Cardiovasc Sci. 2021; 34(4):340341.doi: https://doi.org/10.36660/ijcs.20210183. 